\title{
Consideraciones provisionales sobre el fin del arte
}

Alfonso Castrillón Vizcarra

\section{INTRODUCCIÓN}

Este trabajo tiene como objetivo buscar en las fuentes de la Historia del Arte la formación del sistema de las artes, estudiar su conformación y sus implicancias con la sociedad que lo sostuvo y ver cuáles han sido las causas de su progresivo deterioro y conclusión. La hipótesis que se plantea es que el sistema de las artes que se consolida en el siglo XVIII, sufre una serie de cambios en cuanto a la teoría y la práctica de las distintas artes, haciendo más imprecisos los limites entre ellas, replegándose en lo conceptual más que en la operatividad y el goce estético. Aunque este trabajo se basa en algunos estudios surgidos hace algunas décadas sobre el fin del arte', no quiere decir que se propugne la tesis de su desaparición como práctica humana, sino la conclusión del sistema, por lo cual se plantea la posibilidad de llamar con otro nombre lo que se hace "después" del sistema de las artes.

\section{EL SISTEMA DE LAS ARTES DE OCCIDENTE}

Desde la antigïiedad la cultura greco-latina tuvo un nombre para aquella actividad creativa del hombre por la cual transformaba la materia valiéndose del trabajo de las manos y de su imaginación y de cierta cualidad que la hacía agradable a los ojos y que más tarde se llamó "estética”. Esa actividad se conocía en griego como tejné y en latín como ars y se entendía entonces como "conjunto de reglas y de experiencias técnicas que la mente de hombre ha ideado para producir objetos o representar imágenes de ellos mismos o imágenes de la fantasía”. La práctica “arte” se compone, pues, por un lado, de un operar con las manos, práctica que se puede aprender y desarrollar en grado sumo hasta el virtuosismo, y por otro, de ciertas dotes como la imaginación, la fantasía, el buen gusto, que son innatas. Desde los griegos hasta la invención de la fotografia, esta práctica ha evolucionado aportando nuevas técnicas, materiales e instrumentos que la han llevado a ocupar un sitial de importancia en las academias y los museos, pero en el fondo siguió adhiriendo al concepto aristotélico de mimesis, es decir imitación de la naturaleza. Un repaso rápido de memoria, desde el Efebo de

Danto, Arthur C, After the End of art, 1997. (Traducción castellana: Después del fin del arte. El arte contemporáneo y el linde de la historia. Paidos, Barcelona, 1999).

Morgan, Rebert C. El fin del mundo del arte. Libros del Rojas, Eudeba, Buenos Aires, 1998.

Gardner, James, ¿Cultura o basura? Acento Editorial, Madrid, 1996. 
Kritios (ca. 480 a.C.) hasta un desnudo de Courbet (ca. 1866) nos lo confirma. Se puede suponer que si ha durado tanto se ha debido a una serie de factores culturales, como la tradición, la enseñanza, el comercio, el coleccionismo, que han creado una red de relaciones, potenciando su longevidad. Propongo llamar a esta red de relaciones sistema, entendido como "conjunto de normas, principios, criterios, tales de constituir un modelo codificado al cual referirse". Alguien podrá observar que el concepto de sistema que hemos apuntado se parece al de Ars, (Arte), pero no es lo mismo. Mientras en el arte las reglas tienen que ver con el modus operandi, propio del artista, como de las técnicas que practique, el concepto de sistema abarca, no sólo las técnicas, sino la enseñanza, producción, exposición, distribución y consumo de la obra de arte. Algo más, estas instancias significan interdependencia, no sólo ideológica sino también económica.

CUADRO PRODUCCIÓN DISTRIBUCIÓN Y CONSUMO. (siglos V a.C. - XIX)

\begin{tabular}{|c|c|c|c|c|c|}
\hline & $\begin{array}{c}\text { Antigüedad } \\
\text { Grecia, Roma }\end{array}$ & Medievo & $\begin{array}{c}\text { Renacimiento } \\
\text { Manierismo } \\
\text { Barroco, } \\
\text { Rococó }\end{array}$ & Neoclásico & Romanticismo \\
\hline \multicolumn{6}{|l|}{ PRODUCCIÓN } \\
\hline Taller & $?$ & & & + & + \\
\hline Bottega & & + & + & & \\
\hline Academia & & & + & + & + \\
\hline $\begin{array}{l}\text { Ecole de } \\
\text { Beaux Arts }\end{array}$ & & & + & + & + \\
\hline \multicolumn{6}{|l|}{ DISTRIBUCIÓN } \\
\hline Anticuario & + & & + & + & + \\
\hline $\begin{array}{l}\text { Colecciones } \\
\text { y Museos }\end{array}$ & $\begin{array}{l}\text { Robos y } \\
\text { saqueos }\end{array}$ & $\begin{array}{c}\text { Tesoros } \\
\text { eclesiásticos }\end{array}$ & + & + & + \\
\hline $\begin{array}{l}\text { Galeria de Arte: } \\
\text { Marchands }\end{array}$ & Pinacoteka & & + & + & + \\
\hline \multicolumn{6}{|l|}{$\begin{array}{l}\text { CONSUMO } \\
\text { Encargante }\end{array}$} \\
\hline Estado & + & + & + & + & + \\
\hline Iglesia & & + & + & + & + \\
\hline Particulares & + & + & + & + & + \\
\hline
\end{tabular}


Aunque se sabe que en Grecia la práctica artística se apoyaba en una serie de reglas y experiencias técnicas para ejecutar una obra y la función social del encargo y la remuneración económica tenían gran importancia, sin embargo, no se puede hablar, estricto sensu, de "Sistema de las Artes" hasta el siglo XVIII de nuestra era, donde se completa. Sin duda que los aprendices en Grecia recibían los secretos del arte gracias a un maestro, que podía ser un pintor o un escultor de renombre, que aceptaba los encargos del Estado o de particulares y cobraba por su trabajo ${ }^{2}$. Los historiadores destacan la situación social del artista que en Grecia era considerado un obrero, banausos, término por demás despectivo con el cual se designaba a los obreros metalúrgicos y los alfareros y más tarde a cualquier trabajador manual. Plutarco escribe que ningún joven griego bien nacido querría ser un escultor como Fidias o Polícleto. Es sabido, además, que en Atenas, como en general en el Hélade, el trabajo manual y el comercio al por menor estaban desacreditados ${ }^{3}$. Plinio, sin embargo, nos da a entender que la práctica de la pintura en Roma se cultivó entre las familias ilustres ${ }^{4}$. Por otro lado, el coleccionismo, como instancia del consumo, aumentó notablemente a raíz de los saqueos realizados por los generales romanos en $\mathrm{Grecia}^{5}$, a tal punto que en Roma existía un barrio entero dedicado a los mercaderes de arte y falsificadores $^{6}$. M.V. Marcial, en sus Epigramas, se burla de los coleccionistas y Petronio presenta en su Satiricón al típico advenedizo que se ufana de sus posesiones.

Si el escultor en Grecia era considerado un obrero, era porque realizaba su labor con desgaste físico y sudor, ejercicio impropio de un hombre libre. De ahí proviene la secular distinción entre las artes que podían practicar los ciudadanos libres, es decir liberales, y las mecánicas o serviles ejercidas por los siervos.

Dando un salto al Medioevo, creo que quien mejor define esta situación de diferencia entre las artes es Santo Tomás (1225-1274) que Ilama liberales a aquellas que desarrollan el hábito especulativo de la razón y serviles a las que se ejercitan con las manos ${ }^{7}$. Pasó mucho tiempo para que la pintura y la escultura se liberaran del grupo de las artes mecánicas o serviles y pasaran a formar parte de las artes del diseño a mérito de teóricos con L.B. Alberti (1436), Ghiberti (ca. 1450) y Leonardo de Vinci. Gracias a este último, que se presentaba a sus mecenas como un científico, la situación del artista cambió en el Renacimiento, considerándoselo como un señor que trabajaba placenteramente rodeado de músicos y gente bella. Quisiera que tomáramos nota de dos cosas que caracterizan el genio y la personalidad de Leonardo: el hecho de que considere a la pintura como "cosa metal" y el cambio de status social del artista.

Pero en el Renacimiento se agrega al Sistema una institución que va a tener

El costo de los trabajos escultóricos del Erecteón (fines del siglo V) fue muy bajo: una figura sin accesorios = 60 dracmas (unos 12 dólares); un carro con dos caballos y una figura $=240$ dracmas ( 48 dólares); el precio habitual de una estatua en época de Alejandro era de 3.000 dracmas (unos 600 dólares). (Taylor, 27,28).

Flaceliere, Roberto. La vida cotidiana en Grecia en el siglo de Perícles. Librería Hachette, S.A. Buenos Aires, 1967, p. 136

Plinio. Historia Natural, Libros 34, 35 .

212 a.C. Siracusa; 146 a.C. Corinto; 85 a.C. Sila roba y embarca mármoles y bronces griegos; 73 a.C.

Verro, pretor en Sicilia, se robó la puerta criselefantina del templo de Minerva en Siracusa.

Taylor, Op. cit. p. 36.

Grassi, Luigi; Pepe, Mario. Dizionario della Critica d'Arte. Vol. I, p. 48 
consecuencias significativas, la creación de las academias, que no son asociaciones gremiales, donde se trataba de precios y materiales, como en el medioevo, sino de lugares donde se hablaba del arte, donde se crea una retórica sobre el arte mismo. Así la había concebido Vasari, promotor de la Accademia del disegno en Florencia (1563) con el apoyo del Duque Cosme I. Lo interesante es que la creación de esta Academia trae consigo el decreto que desvinculaba a los artistas de la corporación de los médicos y farmacéuticos a la que pertenecían tradicionalmente. De esta manera se logra la independencia del artista y la conceptualización del valor intrínseco de la obra de arte.

Durante el Manierismo y el Barroco el sistema de las artes guarda las mismas características hasta la creación de la Académie Royale de peinture y esculture de París, en 1648 , donde el sistema se va completando con la enseñanza, los premios, los salones y la compra-venta que, aunque se realizaba fuera y a cargo de los marchands, formaba parte del conjunto ${ }^{8}$.

No podemos dejar pasar dos hechos históricos que tienen que ver con el Sistema de las Artes y que le sirven de contexto y sustento. El primero la formalización de la Estética, como ciencia de la percepción de lo bello, gracias a Alejandro A. Baumgarten (ca. 1735) y el segundo la clasificación de las artes partiendo de un mismo principio, la belleza, de C. Bateaux (1746), es decir Bellas Artes (Escultura, Pintura, Música y Poesía) y Artes Utilitarias (Arquitectura y Elocuencia.) ${ }^{9}$

El Sistema de las Bellas Artes parisino se basaba en la idea de que el arte puede enseñarse siguiendo cierta metodología que partía del dibujo, fundamento de todas las artes. Los alumnos copiaban estatuas originales o moldes famosos para el examen de admisión. Luego diseñaban d'après nature, del natural, con modelos vivos, o de moldes, hasta que la reforma de 1863 instituye los ateliers, talleres, dirigidos por un famoso pintor o escultor. Paralelamente los alumnos deben frecuentar talleres particulares fuera de la Escuela donde aprenderán las técnicas de la pintura.

Los concursos servían de estímulo dentro de la Escuela: los había de "tête d'expression", cabeza de expresión, o "demi-figure", media figura, pero el más codiciado era el Prix de Rome, una beca del gobierno para trabajar en la Academia Francesa de Villa Medici, Roma. La estadía romana venía a ser la coronación de la carrera artística y el comienzo de la fama a la que aspiraban, con razón, los jóvenes artistas. Pero no era fácil. Muchos se presentaban una y otra vez, hasta que lo lograban; otros tenían que admitir, por fin, su fracaso. Hoy resulta inadmisible las pruebas y sacrificios a los que tenían que someterse los postulantes, como permanecer encerrados setenta y dos días, con visitas limitadas, hasta terminar el cuadro para el concurso ${ }^{10}$.

El caso, por ejemplo, del marchand Gersaint, cuya tienda fue inmortalizada por Watteau.

Grassi, Luigi; Pepe, Mario. Op. cit. Vol.I, p. 73.

Grunchec, Philippe. "Le Grand Prix de peinture" Vol. I, Le concours de Prix de Rome de 1797-1863. 


\section{SISTEMA DE PRODUCCIÓN, DISTRIBUCIÓN Y CONSUMO ARTÍSTICO EN FRANCIA SIGLO XVIII}

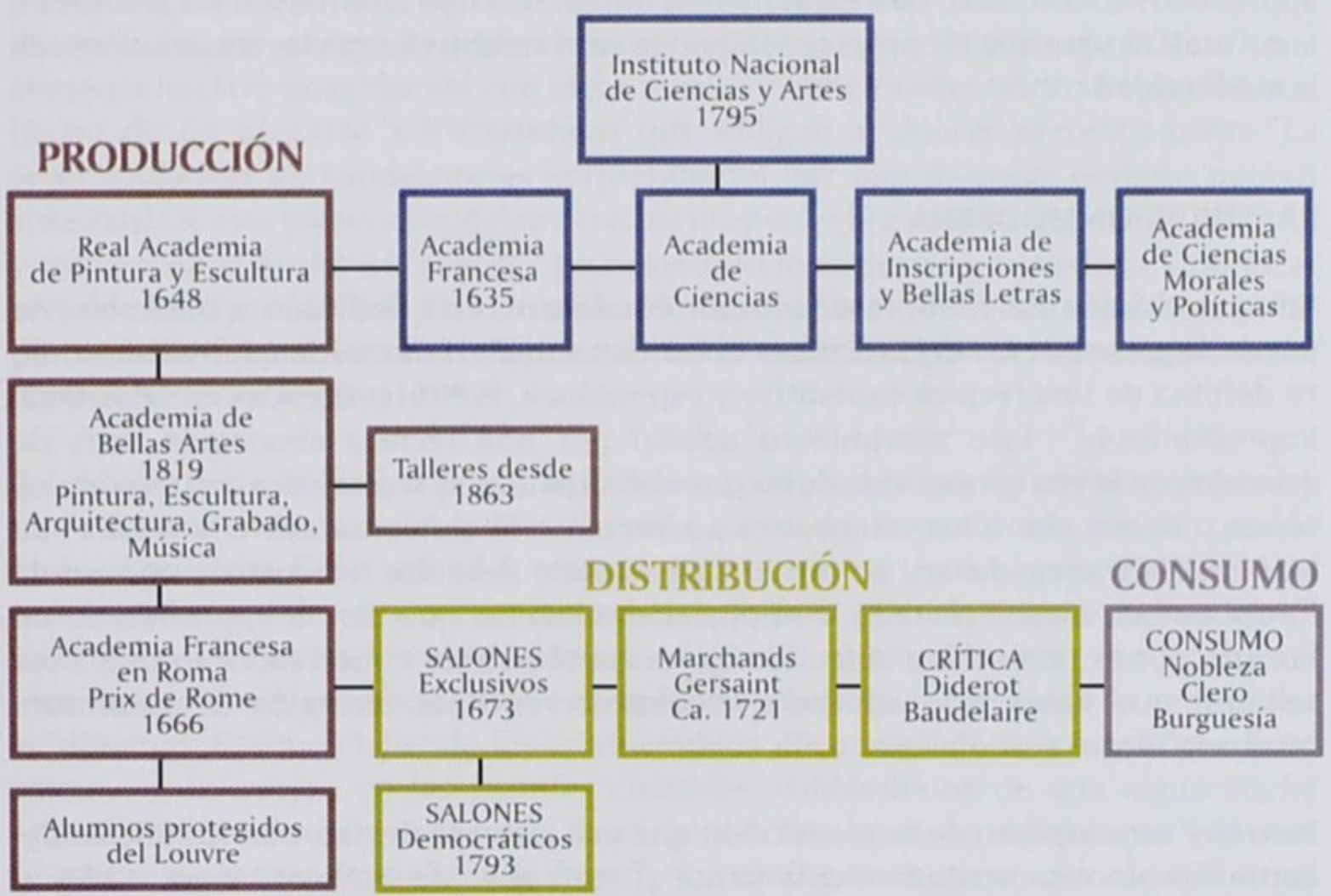

La idea de exponer las pinturas en un lugar acondicionado a propósito se debe a Luis XIV, quien instituyó el Salon des artistes françaises en 1673. Al principio estuvo dedicado sólo a los miembros de la Académie Royale y a partir de 1791 a todos los artistas. El Salon Carré, corazón del Louvre, fue por muchos años el espacio paradigmático de una tradicional costumbre social, las exposiciones de pintura, donde se daban a conocer los artistas y se relacionaban con los marchands. Íntimamente relacionados con esta institución surge la costumbre del catálogo, los primeros redactados por los mismos vigilantes de la sala, y la crítica de los salones, ejercida por pensadores como Diderot (de 1759 a 1781) o escritores como Baudelaire (1845) Así pues, desde Luis XIV hasta el descubrimiento de la fotografía (1822-1837) el Sistema de las Artes mantuvo la coherencia de sus instancias produccióndistribución-consumo y desde el punto de vista estético defendió el principio de mimesis, primero imitando a los clásicos (Ingres), y más tarde, siguiendo la corriente positivista en boga, el naturalismo.(Courbet)

El caso de Gustavo Courbet es interesante (1819-1877): provinciano de Ornams, uno estaría inclinado a pensar que, como hombre de izquierda, su pintura también estaba destinada a superar el realismo, convirtiéndose en un arte revolucionario, de acuerdo a sus ideales políticos. No fue así: sus colores bituminosos y apagados y su testaruda lucha tratando de réndre la nature y dominarla a su voluntad, cuando ya la fotografia se convertía en el ojo infalible del mundo, lo pusieron frente a un impasse que no pudo resolver. Delacroix, hombre de la generación romántica anterior y aristócrata, desde el punto de vista del color y la técnica, fue un verdadero revolucionario, auque usara 
tarro y levita. Si Courbet no pudo resolver el problema les tocó a los Impresionistas dar el salto: no se trataba de representar el mundo natural como era, sino como lo veían nuestros ojos, con una atmósfera de por medio, de manera imprecisa y siempre aproximativa. Es curioso que estas nieblas imprecisas que distribuyen los colores en la naturaleza para que el ojo los recomponga en el cerebro fueran las anunciadoras de la modernidad.

\section{LACONDICIÓN MODERNA}

Aunque el Salón de 1846, reseñado por Baudelaire, está dedicado a Delacroix, no puede negarse que las explicaciones del crítico sobre el color en la naturaleza, como su defensa de una técnica expeditiva y espontánea, fueron proféticas en relación al Impresionismo". Este movimiento apostó por una técnica abocetada, más de acuerdo con la vertiginosa vida de las grandes capitales, que plasmara con rapidez los temas urbanos como los campestres a plein aire. "El almuerzo sobre la hierba" de Manet (1863) escandalizó, no por el desenfadado desnudo femenino ${ }^{12}$, sino por la forma en que estaba pintado, con pinceladas sueltas que dan la impresión de un boceto, por lo tanto inacabado. Eso enervaba al público conservador asiduo a los salones, que había sido educado visualmente con los ejemplos de la pintura "acabada" de los académicos.

Pero hay otro aspecto de la producción que nos interesa destacar en los inicios del impresionismo: su actitud suicida frente al mercado. Me explico: Monet, Sisley o Renoir pintaron pensando en llevar adelante sus propuestas visuales sin preocuparse del mercado. La vida del primero fue, en sus comienzos, de continuas privaciones y de extremada pobreza, felizmente paliada por la asistencia de sus amigos ${ }^{13}$. Sólo años más tarde (1886) y gracias al marchant Paul Duran-Ruel, los impresionistas se harán conocer en Inglaterra y Estados Unidos y la situación cambiará para Monet ${ }^{14}$.

Pero volvamos a Baudelaire. No hay duda de que el primero que siente en el aire du temps algo diferente que creaba una brecha entre el pasado y el presente fue el autor de "Las flores del mal", y que llamó modernidad". En los trabajos críticos de Baudelaire la palabra moderno aparece, al principio, asociada al movimiento romántico, como puede verse en el Salón de 1846, y es interesante destacar, para los que quieren seguir la evolución de su pensamiento, cómo en este Salón define la crítica como "parcial, apasionada, política, es decir realizada desde un punto exclusivo, pero que sea el punto de vista que abre mayor número de horizontes"16. Sin embargo la Exposición Universal de 1855 pone al crítico frente a un problema que su exclusivo criterio

\footnotetext{
“...es bueno que los toques no estén combinados materialmente sino naturalmente a una distancia deseada, por la ley simpática que los ha asociado". Baudelaire, Charles. El Arte Romántico, Editorial Schapire, Buenos Aires, 1954. p. 13.

"El nacimiento de Venus" de Cabanel, comprado por Napoleón III en el Salón de 1863, fue más provocativo que "El almuerzo sobre la hierba".

Rewald, John. Hitoire de l'Impressionnisme. Albin Michel, Paris, 1955. Vol. I, p. 212.

Ibidem. Vol. II, p. 172. También: Lethève, Jacques. La vie quotidienne des artistes francais aux XIX siècle.

Hachette, (Francia) 1968, p. 169-170.

Como bien hace notar Glusberg (Origenes de la Modernidad, nota 1, pág. 208) la palabra modernidad ya se encuentra en las "Memorias de Ultratumba" de Chateaubriand, editadas en 1849-50.

Salón de 1846, en Obras Completas, edición Aguilar, 1963, p. 476.
} 
juvenil no había previsto, el arte de otras naciones y por lo tanto la relatividad de los juicios estéticos. La salida es genial, como movida intelectual y por el valor humano de su reconocimiento: Baudelaire admite que para escapar a las continuas apostasías filosóficas, frente al arte de otras naciones se contentará con "sentir"17. Hay que destacar en este ensayo la preferencia de Baudelaire por "el cosmopolitismo" que alimenta nuestra imaginación con ideas nuevas y obliga a identificarse con ellas y el hecho de no plegarse a los sistemas que obligan a abjurar perpetuamente. La recomendación de Baudelaire es sorprendente: hay que inventar siempre nuevos sistemas! De esta manera Baudelaire crea su propia regla e incita a alejarse de lo trivial y convencional (le chic e le poncif) ${ }^{18}$, promoviendo lo exclusivo y novedoso. Con estas ideas de base ya está listo para lanzar su teoría sobre la modernidad expuestas en "EI pintor de la vida moderna", trabajo comenzado entre 1859-60, pero publicado en Le Figaro en tres entregas en 1863.

Baudelaire parte de la idea de que lo bello está compuesto por un elemento eterno y uno relativo, circunstancial que es la época, la moda, la moral o la pasión...por lo tanto el presente tiene sobrados motivos para que los artistas se ocupen de él. Hay que recordar que el rudo Courbet reclamaba lo mismo, pero el presente de Baudelaire es el que se vive en las grandes ciudades, no en el campo, y el hombre moderno es el mundano, el dandy cosmopolita que comprende la belleza del presente: la multitud es su dominio. Estamos lejos de los aristocráticos decorados de Grecia y Roma, para caminar a la carrera en las grandes ciudades, cuidándonos de que algún coche apresurado nos lleve de encuentro. Baudelaire define la modernidad como "obtener lo eterno en lo transitorio", en lo fugaz y lo contingente, convencido de que estas características de la vida del hombre moderno necesitan de un basamento moral que les asegure la eternidad. Más tarde, con el surgimiento de los nuevos medios de comunicación se demostraría que la modernidad no era eterna y que, como el ave Fénix, moría y renacía de sus mismas cenizas. Lo que quiero decir es que Baudelaire, reivindicador del presente como Courbet, no se imaginó nunca el alcance de su teoría de la modernidad, condición que llevaba dentro los genes de la fugacidad y la moda, el continuo cambio y la novedad de la mano de la creciente industria liberal.

Otra consecuencia, relacionada con el arte de la pintura se deduce de la condición moderna: la plasmación rápida de las ideas sobre el lienzo. Este argumento, que tiene que ver directamente con la técnica, ya se anuncia en el artículo sobre Delacroix de "El Arte Romántico" ", pero se desarrolla con más amplitud en "El pintor de la vida moderna" cuyo paradigma es Constantin Guys, dibujante y acuarelista, reportero que cubrió los eventos más importantes de la política y la vida social de Europa en la época de Baudelaire. Y desde luego, un reportero sin cámara fotográfica como era Guys, que contaba sólo con un lápiz heroico, tenía que desarrollar una técnica rápida, expeditiva, que tradujese lo más rápido posible sus ideas de la cabeza al papel, de tal suerte que "la ejecución ideal, se vuelva tan inconsciente, tan fluida como lo es la digestión para el cerebro del hombre con buena salud que ha comido" ${ }^{20}$. Frente a los dibujos de Guys, que tienen la apariencia de estar suficientemente acabados,

${ }^{17}$ Exposición Universal de 1855, en Op. cit. p. 534.

Salón de 1846 , Op. cit. p. 509.

19 "Una vez (Delacroix) dijo a un amigo mío:-Si no sois bastante hábil para hacer el croquis de un hombre que se arroja por la ventana, en el tiempo que pone en caer desde el cuarto piso al suelo, no podréis nunca producir grandes obras". Op. Cit. p. 27

${ }^{20}$ Baudelaire, Charles. El pintor de la vida moderna. Librería Yerba, Caja Murcia, Murcia 1995, p. 98. 
Baudelaire se lanza a defender abiertamente el boceto ${ }^{21}$, que adquiere rango artístico con los impresionistas. Y en este trabajo se suceden unos tras otros los argumentos a favor del dandi, del maquillaje, que le sirve para hacer bien notoria la dicotomía naturaleza/arte, para terminar con una apología de los coches, no de su tecnología todavía rudimentaria frente a la locomotora, sino de su imagen visual en movimiento que crea en Baudelaire un gran placer estético ${ }^{22}$. Pero Baudelaire no tuvo en Guys un ejemplo apropiado para su aguda apreciación de la simultaneidad de la visión, ya que el reportero sin cámara que era Guys, representa el movimiento de sus coches jalados por caballos en vistas congeladas. Sólo los futuristas hubiesen colmado las expectativas de Baudelaire. Esto confirma la idea de que Baudelaire fue un visionario sin ejemplos en su momento. Inventó la teoría del Impresionismo tratando de explicar los méritos de Delacroix; lanzó la teoría de la modernidad valiéndose del ejemplo de Guys y murió antes de ver los avances de Manet, Monet y Pizarro, perfectos ejemplos de "pintores modernos".

No es que descubriera en los dibujos de Guys algún asomo de "simultaneidad de visión"; él, como hombre de la metrópoli, sumergido en el tráfago de la masa y los coches, embriagado por su condición moderna, la inventa! $!^{23}$ Parafraseando sus propias palabras con que termina el estudio sobre Guys, podemos decir que Baudelaire: "Buscó por todas partes la belleza pasajera, fugaz, de la vida presente, el carácter de lo que él llamó modernidad, mostrando en sus trabajos "el sabor amargo o embriagador del vino de la Vida" ${ }^{24}$.

\section{LA PERCEPCIÓN DEL TIEMPO EN LAS ARTES PLÁSTICAS.}

La indicación del movimiento es quizá la manera más natural de expresar el tiempo en las artes plásticas. El movimiento es virtual en la pintura como en la escultura, tiene "existencia aparente y no real" ${ }^{25}$. Benvenuto Cellini alegaba que la escultura era más completa que la pintura porque se la podía apreciar desde diferentes ángulos, dándonos siempre nuevos perfiles de lo representado. Si el movimiento es virtual en la escultura, es real, sin embargo, en la persona que la rodea. El observador de una escultura exenta le comunica su tiempo en el trayecto de 360 grados que le dedica. Desde la antigüedad hasta el siglo XIX aquello que definía la naturaleza de la plástica era su inmovilidad, y esto era por demás obvio, ya que las obras adquirian el aura de lo sagrado y lo conmemorativo: la inmovilidad era el estado de lo sagrado en la Tierra, la postura hierática del héroe desaparecido; pero algo más, su naturaleza de arte, sea que lo representado esté sobre un pedestal o en una pared o en un bastidor. El tema representa algo que tuvo vida, pero no pertenece a la vida azarosa y trivial de los mortales: pertenece al mundo del arte, al mundo de los museos y por lo tanto a la eternidad. Estas eran las ideas dominantes desde la antiguiedad hasta el siglo XIX.

\footnotetext{
Op.cit. p. 99.

Op.cit.p. 137

Marinetti diría más tarde: "Un automobile da corsa col suo cofano adorno di grossi tubi simili a serpenti dall'alito explosivo....un automobile ruggente, che sembra correre sulla mitraglia, é piú bello della Vittoria di Samotracia". F.T. Marinetti. Teoria e invenzione futurista. Mondadori Editori, 1968. p. 10.

${ }^{24}$ Baudelaire, Charles. El pintor de la vida moderna. Edición citada, p. 137.

5 "Virtual". Diccionario de la Real Academia, XXI edición, año 2001.
} 
Salvo la tentativa de los futuristas de representar el movimiento valiéndose de la repetición de la figura en la superficie plana del cuadro, creando un ritmo evidente, como también el Desnudo descendiendo una escalera de Duchamp, influidos sin duda por la fotografía estroboscópica ${ }^{26}$, la pintura se interesó de manera esporádica por la representación del movimiento ${ }^{27}$. El movimiento-tiempo es una característica de lo cotidiano y perecible, y el arte, como hemos señalado, pertenece tradicionalmente al mundo de lo inmóvil, por su aspiración a lo eterno. Nuestra tesis es que no resulta connatural a las artes plásticas la representación del tiempo, salvo en los casos de representación virtual que hemos señalado; pero si no se da en las imágenes, se evidencia en las técnicas, en la operatividad, en el modo de hacer. Me explico.

La percepción que el hombre europeo tiene del tiempo comienza a diferenciarse de la tradicional renacentista a partir de la Revolución Industrial: la invención de la locomotora, la creación de ciudades satélites lejos de los centros urbanos, la división del trabajo, etc. hacen posible la visión moderna de la vida, donde la aceleración es un factor relevante que se traduce en todas las acciones del hombre. De las artes tradicionales es sin duda la pintura la más afectada por el nưevo ritmo temporal de la vida moderna: ya hemos examinado el pensamiento de Baudelaire al respecto. Lo que cambia no es la representación del tiempo en sí, sino el tiempo de ejecución (la manera de producir) que evoluciona desde las lentas facturas académicas hasta los "chorreados" de Pollock. La operatividad artística va de acuerdo con el modo de producir de la industria moderna, cada vez más eficiente, rápido y económico, pero que ofrece al mercado artefactos de materiales menos durables y deleznables que sin embargo retroalimentan su cadena de producción. El arte, entonces, se convierte en efimero y pierde su carácter "eterno".

\section{LAS VANGUARDIAS HISTÓRICAS}

La mayoría de los historiadores del arte contemporáneo están de acuerdo en utilizar el nombre de vanguardia, tomado del repertorio de la guerra, para designar a aquellos movimientos artísticos de avanzada que generalmente iban en contra de la tradición y las academias. En este sentido el primer movimiento vanguardista stricto sensu es el Impresionismo: el carácter abocetado de sus cuadros pintados al aire libre, el estudio de la ley de los colores complementarios, la acción temeraria de trabajar para un público y un mercado inexistentes, lo pone a la cabeza de los movimientos cuestionadores del pasado. Sigue una lista de nuevas tendencias como el Neo Impresionismo, el Post Impresionismo, Nabis, el Fauvismo, el Cubismo, etc. con personalidades fuertes a la cabeza, que aunque proponen técnicas nuevas, terminan acercándose al "arte de los museos", como quería Cézanne. Congregaron grupos raleados y se puede decir que fueron tendencias de un solo protagonista, auque hay que reconocerles una fuerte influencia en los artistas que vendrían más tarde.

\footnotetext{
"Eadweard Muybridge realizó series de fotografias del movimiento humano (1887), valiéndose de dispositivos fotográficos especiales que sirvieron, por ejemplo, a Degas para sus dibujos sobre la manera de caminar de los caballos y más tarde inspiraron a los futuristas Balla y Boccioni y también a Duchamp.

${ }^{2}$ Curiosamente Dinamismo di un cane al giunzaglio de Giaccomo Balla y Desnudo descendiendo una escalera de Marcel Duchamp, son de 1912.
} 
Podríamos llamar a este tipo de vanguardias de filo blando, para distinguirlas de las vanguardias radicales, el Dadaísmo y el Neo Dadaísmo ${ }^{28}$.

El Dadaísmo aparece sucesivamente en Zurich (1916), en Nueva York (1917), Berlín (1918), París (1919) y en medio de la confusión que generó a propósito, sobre su creación, el significado de su nombre y sobre su programa (si lo tuvo), una cosa queda clara y es que fue el movimiento de vanguardia que apareció para arrasar con la tradición artística europea, no solamente desde el punto de vista de las formas y las técnicas, sino con el concepto mismo de arte.

Peter Bürger anota "...los movimientos históricos de vanguardia niegan las características esenciales del arte autónomo: la separación del arte respecto a la praxis vital, la producción individual y la consiguiente recepción individual. La vanguardia intenta la superación del arte autónomo en el sentido de una reconducción del arte hacia la praxis vital. Este no ha sucedido y acaso no pueda suceder en la sociedad burguesa, a no ser en la forma de la falsa superación del arte autónomo $^{29 "}$. Creo que esta declaración de Bürger invita a considerar, de manera realista, sobre el destino y el alcance de las vanguardias históricas y su futura asimilación a los museos. Quizás los vanguardistas no lograron el antiguo ideal de unir arte y vida, creación y recepción colectivas, como dice Bürger, pero abrieron el camino hacia lo conceptual en el arte y esta fue un arma mucho más mortífera que los gritos destemplados de los dadaístas en el café Voltaire, en Suiza, o los vómitos irracionales de los manifiestos de Tzara. Atentó contra la objetualidad del arte de Occidente, contra lo más tradicional y obvio de su naturaleza, su materialidad.

\footnotetext{
${ }^{28}$ Considero que el Futurismo, tal como lo propone Marinetti, con sus bravatas fascistoides y su ensalzamiento de la máquina y la velocidad, adhiere a la visión de un industrialismo mecanizado capitalista, lejano del radicalismo dadaista. Por otro lado, el Surrealismo preocupado en sus búsquedas en el campo de los sueños y el irracionalismo, descuidó el único medio que lo hubiese convertido en una vanguardia radical, al dejar la pintura tradicional por el cine y su lenguaje cinético, apto para dar vida a los temas oníricos. Reconocemos sin embargo algunos ensayos cinemáticos como Le chien andalou de Dali-Buñuel o La sang d'un poete de Cocteau, verdaderos aportes artísticos.

${ }^{\searrow}$ Bürger, Peter. Teoría de la vanguardia. Editorial Península, Barcelona, tercera edición, 2002, p. 109.
} 


\section{CUADRO DE LA SUCESIÓN DE TENDENCIAS O VANGUARDIAS HISTÓRICAS EN EL SIGLO XIX Y XX}

\begin{tabular}{|c|c|c|c|c|c|}
\hline TENDENCIAS & SURGIMIENTO & ARTISTAS & DURACIÓN & $\begin{array}{l}\text { APORTES } \\
\text { TECNICOS }\end{array}$ & $\begin{array}{c}\text { APORTES } \\
\text { CONCEPTUALES }\end{array}$ \\
\hline Impresionismo & 1867 & $\begin{array}{c}\text { Manet, Monet, } \\
\text { Sisley, Pizarro, } \\
\text { Renoir, etc. }\end{array}$ & $\begin{array}{c}\text { Última Expo: } \\
1886\end{array}$ & $\begin{array}{l}\text { Convalidacón } \\
\text { del boceto. } \\
\text { Yustaposición } \\
\text { de los colores. } \\
\text { Pintura "plain air" }\end{array}$ & $\begin{array}{l}\text { Temática de } \\
\text { la vida social } \\
\text { del momento. }\end{array}$ \\
\hline $\begin{array}{c}\text { Neo } \\
\text { Impresionismo }\end{array}$ & 1886 & $\begin{array}{l}\text { Seurat, Signac, } \\
\text { Cross }\end{array}$ & 1890 & Puntillismo & $\begin{array}{l}\text { Teoria del color } \\
\text { Feneon }\end{array}$ \\
\hline $\begin{array}{c}\text { Post } \\
\text { Impresionismo }\end{array}$ & $1888-1890$ & $\begin{array}{l}\text { Cézanne, } \\
\text { Van Gogh, } \\
\text { Gauguin }\end{array}$ & $\begin{array}{l}1902 \\
1890 \\
1903\end{array}$ & $\begin{array}{l}\text { Visión simultánea } \\
\text { Divisionismo } \\
\text { Cloissonnisme }\end{array}$ & $\begin{array}{l}\text { Ver nota (1) } \\
\text { Pintura=expresión } \\
\text { Simbolismo }\end{array}$ \\
\hline Nabis & 1888 & $\begin{array}{c}\text { Denis, Bonnard } \\
\text { Vuillard, Serussier, } \\
\text { Valloton, Maioll }\end{array}$ & $1891-1900$ & Cloissonnisme & Vernota (2) \\
\hline Fauvismo & 1905 & $\begin{array}{c}\text { Matisse, Derain, } \\
\text { Vlaminck, Marquet, } \\
\text { Rouault, etc. }\end{array}$ & 1909 & $\begin{array}{l}\text { Búsqueda del } \\
\text { maximo efecto } \\
\text { cromatico y. } \\
\text { expresivo. }\end{array}$ & Ver nota (3) \\
\hline Die Brücke & 1905 & $\begin{array}{c}\text { Kirchner, } \\
\text { Schmidt-Rottluff, } \\
\text { Mueller, } \\
\text { Beckmann, Heckel, }\end{array}$ & 1913 & $\begin{array}{l}\text { Uso libre del } \\
\text { color, } \\
\text { espontaneidad }\end{array}$ & $\begin{array}{l}\text { Juntar artistas } \\
\text { revolucionarios, } \\
\text { destrucción de } \\
\text { las viejas reglas. }\end{array}$ \\
\hline Futurismo & 1909 & $\begin{array}{l}\text { Marinetti, } \\
\text { Boccioni, } \\
\text { Russolo, Carrá, } \\
\text { Severini,etc. }\end{array}$ & 1916 & $\begin{array}{l}\text { Lineas-fuerza. } \\
\text { Escultura: } \\
\text { compenetración } \\
\text { de los planos, etc }\end{array}$ & $\begin{array}{l}\text { Exaltación de la } \\
\text { máquina y la velo- } \\
\text { cidad,"parole in } \\
\text { libertá", etc. }\end{array}$ \\
\hline $\begin{array}{l}\text { Cubismo } \\
\text { (Analítico) }\end{array}$ & 1909 & $\begin{array}{l}\text { Picasso, } \\
\text { Braque }\end{array}$ & 1911 & $\begin{array}{l}\text { Collage, } \\
\text { grafiados }\end{array}$ & $\begin{array}{l}\text { Guillaume } \\
\text { Apolinaire: } \\
\text { "Los pintores } \\
\text { cubistas"1913 }\end{array}$ \\
\hline $\begin{array}{l}\text { Abstracción } \\
\text { Absoluta }\end{array}$ & 1910 & Kandinsky & & $\begin{array}{l}\text { Desaparición } \\
\text { de la figura }\end{array}$ & $\begin{array}{l}\text { Worringer, "Abs- } \\
\text { tracción y natura- } \\
\text { leza", } 1908 . \\
\text { Kandinsky, } \\
\text { "De lo espiritual } \\
\text { en el arte",1912 }\end{array}$ \\
\hline Orfismo & $1912-1913$ & \begin{tabular}{|c|} 
Delaunay, \\
Duchamp, Picabia, \\
Kupka, Léger...
\end{tabular} & 1913 & $\begin{array}{l}\text { Círculos } \\
\text { dinámicos }\end{array}$ & $\begin{array}{l}\text { Apolinaire: } \\
\text { "Los pintores } \\
\text { cubistas" } 1913\end{array}$ \\
\hline Dadaísmo & $\begin{array}{l}\text { París: } 1915 \\
\text { Zurich: } 1916 \\
\text { Berlín: } 1918 \\
\end{array}$ & $\begin{array}{c}\text { Arp, Tzara, Janco, } \\
\text { Ball. Hausmann, } \\
\text { Heartfield... }\end{array}$ & \begin{tabular}{|l|} 
París: 1920 \\
Zurich: 1919 \\
Berlín: 1920 \\
\end{tabular} & $\begin{array}{l}\text { Fotomontaje } \\
\text { Merzbil } \\
\text { Poemas fonéticos }\end{array}$ & $\begin{array}{l}\text { Anti- } \\
\text { intelectualismo, } \\
\text { Irracionalismo, } \\
\text { Nihilismo }\end{array}$ \\
\hline Surrealismo & 1924 & $\begin{array}{c}\text { Breton, Ernst, } \\
\text { Masson, Arp, } \\
\text { Tanguy, Miró... } \\
\text { Peret, Eluard, } \\
\text { Aragon, Desnos... }\end{array}$ & 1966 & $\begin{array}{l}\text { Frotage } \\
\text { Cadáveres } \\
\text { exquisitos }\end{array}$ & $\begin{array}{l}\text { Adré Breton: } \\
\text { Manifiesto } \\
\text { de } 1924 \text {. }\end{array}$ \\
\hline
\end{tabular}

(1) "La pintura es una óptica, y el contenido de nuestro arte reside en primer lugar en lo que piensan nuestros ojos. (...) "Pintar según la naturaleza no significa copiar el objeto, sino realizar sensaciones cromáticas" (...) "los cuadros serán construcciones que se enfrentan a la naturaleza. En la naturaleza, todo se modela según a esfera, el cono y el cilindro". Hess, Walter. Documentos para la comprensión del arte moderno. Ediciones Nueva Visión. Buenos Aires, 1967, p. 26.

(2) "Acordarse que un cuadro -antes que ser un caballo de batalla, una mujer desnuda, o cualquier anécdota- es esencialmente una superficie plana recubierta de colores juntados en un cierto orden". Denis, Maurice. Theories. Hermann Paris, 1964.

(3) Hess, Walter, Op. cit. p. 56-57. 
Pero para llegar a la desmaterialización del arte se debía, primero, atacar el concepto mismo de arte y esta tarea le tocó a Marcel Duchamp (1887-1968). El creador de los ready-made, comenzó pintando cuadros al óleo de tipo impresionista, luego tentó una especie de simbolismo expresionista, para terminar la época de sus búsquedas componiendo cuadros donde las figuras se sobreponian en una suerte de visión simultánea, tomada del cubismo, como Joven triste en un tren, de 1911, que anuncia su famoso Desnudo descendiendo una escalera, de 1912. Luego vinieron El rey y la reina, rodeados de desnudos rápidos y Casada, también del año 1912, con los que demostró Duchamp su pericia para crear composiciones abstractas, cercanas a figuraciones orgánicas, de gran efecto visual. Pero si contra algo luchó denodadamente Duchamp fue con la "visión retiniana", es decir el placer de los ojos que había sido el deleite de la pintura tradicional y especialmente de los impresionistas. En adelante su preocupación será crear objetos que no tengan que ver con la tradición artística de Occidente y comenzará a ensamblar cosas encontradas, como el Taburete con rueda de bicicleta, de $1913^{30}$, y otros, entre los que La fuente, (el urinario), de 1917, es el más agresivo y conocido de sus ready-made.

Hay suficientes pruebas de que Duchamp, con la invención de los ready-made, no quiso hacer "obras de arte". "La palabra ready-made -dice- se me presentó en ese momento, parecía adecuarse perfectamente a cosas que no eran obras de arte, que no eran esbozos, que no se aplicaban a ninguna de las expresiones aceptadas en el mundo artístico" $"$ ". "El ready-made era un objeto manufacturado, de producción en serie, carente de toda cualidad estética, elegido en función de la indiferencia visual y, al mismo tiempo, de la total ausencia de buen o mal gusto" ${ }^{\text {"32 }}$. Creo que Duchamp, en esa época, no estaba consciente del alcance de su propuesta, pero lo cierto es que tuvo serias consecuencias en el futuro, ya que el escoger un objeto hecho en serie significaba traerse abajo el concepto de creación individual y, por otro lado, el uso de lo que él llamaba "indiferencia visual" atentaba contra el esteticismo raigal del arte de Occidente $^{33}$. ¿Cómo llega a esta situación? Luego de diez años de pintura Duchamp se harta de ella, piensa que no se puede seguir pintando al óleo, que el cuadro no puede ser un motivo decorativo para el comedor o la sala, y por lo tanto, insta a encontrar otras fórmulas. Desde estas reflexiones se pregunta "ise pueden hacer obras que no sean obras de arte?" Aunque con inevitables contradicciones, Duchamp trató de ser fiel a sus principios y su obra maestra el "Gran Vidrio", no quiso ser una pintura para mirar sino para expresar una idea. De hecho se ha desterrado de esa obra toda impresión retiniana y la historia de la novia desnudada por sus solteros está planteada como un diagrama de líneas y curvas, con apariencia de plano industrial, que no tiene relación con la pintura tradicional. Los objetos a-artísticos de Duchamp prepararon el camino al arte conceptual y por lo tanto la conclusión del sistema de las artes de Occidente.

\footnotetext{
${ }^{30}$ Según Duchamp, "La palabra ready-made no apareció hasta 1915, cuando fui a Estados Unidos". (Declaraciones de Duchamp a Pierre Cabanne, En: Conversaciones con Marcel Duchamp, Ed. Anagrama, Barcelona, 1972.) Farmacia, de 1914, ya aparece firmado.

Cabanne, Op. cit. p. 71.

${ }^{2}$ Las cursivas indican la declaración de Duchamp a Cabanne. En: Tomkins, Calvin. Duchamp. Anagrama, 1999, p. 175.

"La literatura de la época nos da un ejemplo parecido: se trata del "acto gratuito" de André Gide formulado en su novela "Les caves du Vatican" (1913). "Asi como Lafcadio empuja al vacío a Amedée Florissoire, desde un tren en marcha de Nápoles a Roma, por puro gusto, como acto gratuito, asi Duchamp tira al vacio la intencionalidad estética en sus readymade". Castrillón Vizcarra, Alfonso. "Reflexiones sobre el arte conceptual en el Perú y sus proyecciones". En: ¿El ojo de la navaja o el filo de la tormenta? Universidad Ricardo Palma, Lima, 2001.p. 181.
} 
Pero no fue tan rápida la llegada del Neo dadaísmo y el conceptual, tenían que aparecer el expresionismo abstracto, la llamada Escuela de Nueva York, toda una época en que las propuestas de Duchamp se dejarían de lado y él mismo entraría en el limbo del olvido por algún tiempo. Cabe preguntarse ¿qué pensaba el viejo vanguardista de los expresionistas abstractos? Según su biógrafo, Kalvin Tomkins, Duchamp no sentía especial interés por la obra de Pollock, como de los artistas de la asi llamada Escuela de Nueva York, y cuenta que esa actitud suya puede colegirse de un incidente que se produjo cuando Peggy Guggenheim lo llamó para que la aconsejara cómo colocar un mural de Pollock que había sido destinado para el vestíbulo de su casa; como no cabía en la pared, Duchamp recomendó, sin inmutarse, cortarle un buen palmo ${ }^{34}$. En otra oportunidad le escribió a un amigo: "Todo el panorama artístico se encuentra en un nivel tan bajo, (...) y está tan comercializado...que el arte o cualquier cosa que tenga que ver con él constituye la forma más baja de actitud de estos tiempos" ${ }^{\text {.35 }}$. Otro argumento en apoyo de su desinterés por el Expresionismo Abstracto sería la naturaleza "retiniana" de esa pintura, que Duchamp consideraría un paso atrás en la historia del arte contemporáneo.

\section{LA CARRERA DE LAS NUEVAS VANGUARDIAS}

Luego que Duchamp inoculara el virus a-artístico habría que esperar algún tiempo; no prendió tan rápidamente. En los 50, los estadunidenses estaban buscando una imagen en el mundo del arte y ganar para Nueva York la primacía de capital del arte, dejando de lado a París. Estaban, por lo tanto, lejos de una teoría que acabase con el arte y al contrario pusieron toda su fuerza en levantar el prestigio de la nueva tendencia, el Expresionismo Abstracto, y especialmente en fabricar al héroe que necesitaban: Jackson Pollock.

Del Expresionismo Abstracto, (Arte Póvera, Rauschemberg de 1957; Oldembug en The Street, 1960; Fluxus y Beuys; la nueva danza de Merce Cunninghann, John Cage, Nam June Paik; la Nueva Figuración; Rauschemberg del 64, ganador de la Bienal de Venecia; el movimiento Pop. Andy Warhol; Minimalismo; Op art; Abstracción excéntrica; Land Art; Body Art; Hiperrealismo y otros ismos) hasta el arte conceptual, no pasaron muchos años. En los 60 se llamó Neo dadaísmo a aquel accionar desenfadado que echaba mano de los ejemplos de Duchamp y que él consideraba, y con razón, una "salida fácil". "Cuando descubrí los ready-made, pensé que me estaba oponiendo a la estética”, le decía Duchamp a Hans Richter, y seguía: "El neodadá ha cogido mis ready-made y les ha encontrado una belleza estética. Les arrojé a la cara el porta botellas y el urinario como un reto y ahora resulta que los admiran por su belleza estética”36. Pero no todo fue aprovechamiento fácil. El caso de Joseph Kosuth, con tangencias con Duchamp, ejemplifica el otro camino extremado hacia desmaterialización del objeto, o conceptualismo, desde su One and three chairs (1965) hasta su Titled (Art as Idea as Idea) (1967) "Generalizando dice S. Marchan es posible decir que la obra conceptual carece de una realidad estética formal en el sentido de una pintura o de una escultura" ${ }^{37}$.

\footnotetext{
${ }^{34}$ Tomkins, Kalvin. Duchamp. Anagrama, Barcelona, 1999, p. 402.

${ }_{35}^{35}$ Carta a Francis Steegmuller en Tomkins, Op. cit, p. 464.

${ }^{36}$ Tomkins, Op. cit. p. 460.

${ }^{37}$ Marchan, Simón. Del arte objetual al arte de concepto, 1960-1974. p. 303.
} 
Pero hay que tener en cuenta que la ausencia del objeto no significa el final del arte; ha sucedido una "transustanciación" del concepto de arte (tradicionalmente adherido al objeto) que ha pasado a la idea. Es más, yendo más allá que Duchamp, los conceptualistas han propuesto que todo lo que el artista hace es arte, que todo lo que toca, como el rey Midas, se convierte en arte, que todos somos artistas (Beuys) y que todos merecemos el museo, templo consagrador de la inventiva humana. Pero la idea del a-arte de Duchamp se ha desvirtuado: al lanzar esa idea, el creador de los readymade se traía abajo la noción de objeto aurático y sujeto de comercio; en otras palabras, creaba otro concepto que instaba a volver a considerar el valor de uso de los objetos y no su valor de cambio, como mercancía. El considerar sólo los aspectos estéticos de la creación individual nos ha distraido siempre del aspecto venal que esconde el arte tradicional, la función que cumplen las galerías de arte y los museos. Pero, paradójicamente, los ideales de las vanguardias históricas se quedaron en las puertas de los museos, instituciones que fagocitan los objetos desestabilizadores, vaciándolos de sus contenidos, para convertirlos en neutrales piezas de arte.

Después de Duchamp, los artistas de los centros de poder, han acelerado su ritmo productivo planteando miles de propuestas, andando por caminos trillados, anodinos, desgastados y como no pueden inventar más, ha llegado la hora del agotamiento. En nuestra época no interesa crear algo nuevo, motor y palanca del arte y del comercio artístico de generaciones anteriores; el interés se ha volcado en las citas, las regurgitaciones de estilos pasados, con ligeras modificaciones, que ha dado en llamarse "postmodernidad". Según mi parecer, el sistema de las artes de Occidente se ha cerrado por agotamiento. Esa dinámica que lo hacia correr hacia nuevas propuestas, pensando siempre en el futuro, ya se acabó.

\section{DESPUÉS DELARTE}

El controvertido tema del final del arte fue tratado por Hegel en un revelador párrafo de su "Estética" ${ }^{38}$, donde asegura que el arte ha perdido para nosotros (hablaba a mediados del siglo XIX) su verdad y su vida. Sin hacer un recuento de los estudios que desde entonces han tratado dicho tema, nos referiremos aquí al trabajo de Arthur Danto $^{39}$, que por los mismos años en que Hans Belting ${ }^{40}$ trataba sobre "el arte antes de la época del arte", (es decir, el arte religioso antes del Renacimiento, donde no existía conciencia del arte como "arte"), supone que debía haber, consecuentemente, un arte después del "arte". En el primer capítulo del libro de Danto queda claro que el hecho de haber llegado a una "autoconciencia" del arte (recordemos la premonición

\footnotetext{
${ }^{35}$ Hegel, Jorge Guillermo Federico. De lo Bello y sus formas. (Estética) Espasa Calpe, Cuarta edición. Madrid, 1969, p. 33. "El arte con su al to destino es algo ya pasado: ha perdido para nosotros su verdad y su vida. Lo consideramos de manera demasiado especulativa para que vuelva a ocupar en las costumbres el puesto elevado que ocupaba en otro tiempo. Razonamos nuestros goces y nuestras impresiones; todo es ya, en las obras de arte, materia de critica o tema de observaciones. La ciencia del arte, en semejante época, es una necesidad mayor que en aquellos tiempos en los cuales tenía el privilegio de satisfacer plenamente y por sí mismo la inteligencia. Hoy parece invitar a la filosofia a que se ocupe de él; no para que ésta le conduzca a su fin, sino para que estudie sus leyes y profundice en su naturaleza."

"Danto, Arthur, After the End of art, 1997. (Traducción castellana: Después del fin del arte. El arte contemporáneo y el linde de la historia. Paidos, Barcelona, 1999)

${ }^{* 0}$ Belting, Hans. Likeness and Precence: A history of the Image before the Era of Art, Chicago, University of Chicago Press, 1984. Citado por Danto, Op. cit. p. 40.
} 
de Hegel) significa que la historia (del Arte) ha concluido y además, otra aserción importante, que las obras producidas "después del arte", pueden ser consideradas como meras cosas, sin exigir el estatus del arte ${ }^{41}$.

Según lo antedicho, tenemos entonces un arte antes de la era del arte (según Belting desde la antiguiedad hasta, aproximadamente, 1400 d. C.); la era del arte, desde el Renacimiento hasta, más o menos 1960, donde se nota un agotamiento y las vanguardias disociativas operan la transformación del objeto en "idea”, y, por último, ciertas manifestaciones humanas después de la era del arte.

A estas alturas el lector, que ha seguido pacientemente mis argumentos, comprenderá cuáles son mis intenciones después de haber demostrado cómo el arte de occidente ha seguido su carrera hacia el abstracto hasta acabar con el objeto. El esquema de Belting-Danto, al confirmar, sin embargo, que hemos llegado a una época que podría denominarse post artística, deja abierta la pregunta: ¿Qué son las expresiones humanas antes Ilamadas arte y cómo Ilamarlas en adelante en la época después del arte?

Mi tesis puede formularse de la siguiente manera: Se ha probado que hemos llegado al final de una época artística y estos síntomas terminales no sólo tienen que ver con los creadores, sino con todo el sistema, el Sistema de las Artes de Occidente, que ya se cerró por agotamiento y por haber confiado su ser a la filosofía. Cuando el arte se aleja de la vida y comienza a hablar de sí mismo, el arte llega a su fin. (Hegel) Esta idea puede representarse de la siguiente manera:
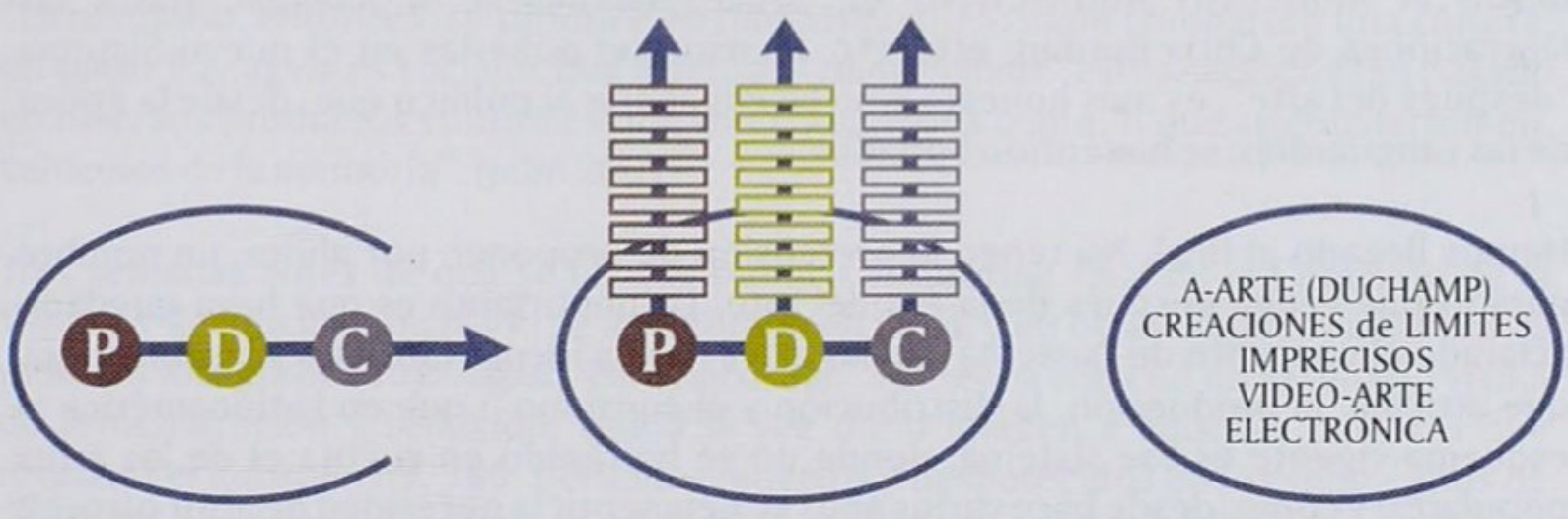

El Sistema productor de objetos está rodeado de una elipsis abierta dentro de la que se encuentra la producción, la distribución y el consumo, orientados hacia la salida por una flecha que indica su proyección y su carrera hacia el futuro. Todo el sistema está impelido por esa dinámica, pero cuando el objeto desaparece, termina "la fiebre del oro" y la elipsis se cierra: ya no hay necesidad de correr haciendo propuestas visuales, llamadas arte. ¿Qué sucede? Nace otro sistema que tiene características diferentes al tradicional: 1.- La tecnología ha suplantado al lápiz y los pinceles y la enseñanza se imparte en escuelas técnicas. Además la obra es inmaterial. 2.- La distribución se realiza en el ciberespacio, y 3.- El consumo de la obra no cuesta, puede ser modificada por el cibernauta y la fruición es individual y no me extrañaría que pronto sea experimentada directamente en el cerebro.

\footnotetext{
${ }^{41}$ Danto, Op.cit. p. 26-27.
} 
Este sistema, desde luego, tiene su prehistoria, cuyos primeros capítulos incluyen el a-arte de Duchamp, y, más adelante, el conceptual y la desaparición del objeto. Podría seguir el capítulo de las creaciones de "límites imprecisos", teatro/performance; cine/ documental/vídeo; pintura/escultura, etc. hasta llegar a los objetos virtuales y las proyecciones lumínicas que provienen de la revolución electrónica ${ }^{42}$.

Pero, al decir que el Sistema se cerró no significa que el arte ha muerto. En el Sistema de las Artes de Occidente se seguirá produciendo "arte", de acuerdo a las necesidades visuales y de adorno de la población: paisajes, desnudos, retratos; naturalismos, abstracciones, expresionismos, etc. Si miramos la figura $\mathrm{N}^{\circ} 2$, veremos que la producción, en lugar de correr hacia el futuro, crecerá hacia lo alto, como los edificios de una ciudad amurallada. Será como cierto arte de Oriente donde se ha llegado a una refinada especialización y ningún "artista", (se entiende ningún artista tradicional), corre en pos de la novedad y la moda, sino que identificados fuertemente con sus tradiciones, llegan al virtuosismo, uno de los objetivos de su carrera. Para ellos eso significa ser artista y ninguno se siente menospreciado conservador o tradicionalista.

En mi opinión, los creadores pertenecientes al nuevo sistema, no tienen por qué llamarse artistas y lo que hacen merecería otro nombre, desde el momento que sus obras o acciones no han sido creadas siguiendo la téjne tradicional del Sistema. Los cadáveres "plastinados" del Doctor Gunther von Hagens, los animales flotando en formol de Damián Hirst, la latita de Piero Manzoni conteniendo Merde d'artiste, las acciones de Joseph Beuys, como en I like America and America like me, donde se encerró varios días en la galería con un coyote; y podríamos seguir con una lista interminable desde el inofensivo Autorretrato de Bruce Nauman as a fountain, hasta las laceraciones de Chris Burden, etc., etc. Pienso que ponerlas en el nuevo Sistema "después del arte", es más honesto y no se engañaría al público que, desde la época de las vanguardias, se ha sentido burlado.

Hemos llegado al final. No tengo la pretensión de proponer, por ahora, un nombre para lo que venga después de la era del arte. Lo importante es que haya quedado aclarado el concepto de "sistema" de las artes de Occidente (SADOC) y las funciones que articula, la producción, la distribución y el consumo ${ }^{43}$; que en Latinoamérica el esquema vigente es ese sistema, donde no se ha tenido en cuenta el de las artes populares; y cómo, desde hace varios años se deja sentir la necesidad de abrir otro, en el que se junten todas aquellas manifestaciones que están, por su naturaleza, fuera del SADOC, el mundo de la electrónica, entre otros, que en el Perú recién está desarrollándose ${ }^{44}$. A los jóvenes operadores de este nuevo sistema va dedicado este trabajo.

\footnotetext{
42 "Pero hoy estamos en los umbrales de una metamorfosis del arte todavia más profunda y radical. En primer lugar, por los componentes con que las nuevas técnicas operan: la luz y la información (analógica o digital), que implican una tendencia a la desmaterialización del objeto o, siendo más precisos, a la aparición de nuevas formas de materialidad." Jiménez, José. Teoria del arte. TecnosAlianza Editorial,

4 Juan Acha, Néstor García Canclini y Mirko Lauer trabajaron esta idea desde el final de la década del 70.

"Para todo lo relacionado con el video/arte electrónico ver Perú/video/arte/electrónico, publicado por ATA (Alta Tecnología Andina) y la Universidad Ricardo Palma, Lima, 2003.
} 